\title{
A case of coconut bezoar and Meckel's diverticulum
}

\author{
R. E. LAWRENCE \\ M.B., Ch.B. \\ Department of Cardiovascular Medicine, East Birmingham Hospital, Bordesley Green East, \\ Birmingham B9 5ST
}

\begin{abstract}
Summary
A 23-year-old male, operated upon for supposed pelvic appendicitis, was found to have a Meckel's diverticulum with intestinal obstruction due to a coconut bezoar.
\end{abstract}

\section{Case report}

A 23-year-old shop assistant presented with a 12-hr history of intermittent, severe, low-central abdominal pains, colicky in nature. He had been anorexic throughout the day, drinking only water, had vomited clear fluid 3 times and had felt feverish and nauseated. He had passed small quantities of loose stool 4 times that day.

During the previous evening he had eaten the pulp of an entire coconut.

On examination he was flushed, though apyrexial, and obviously distressed by pain. His tongue was clean but the fauces of his mouth were injected: there was no foetor.

His abdomen was thin with nothing abnormal to find apart from supra-pubic tenderness with rebound

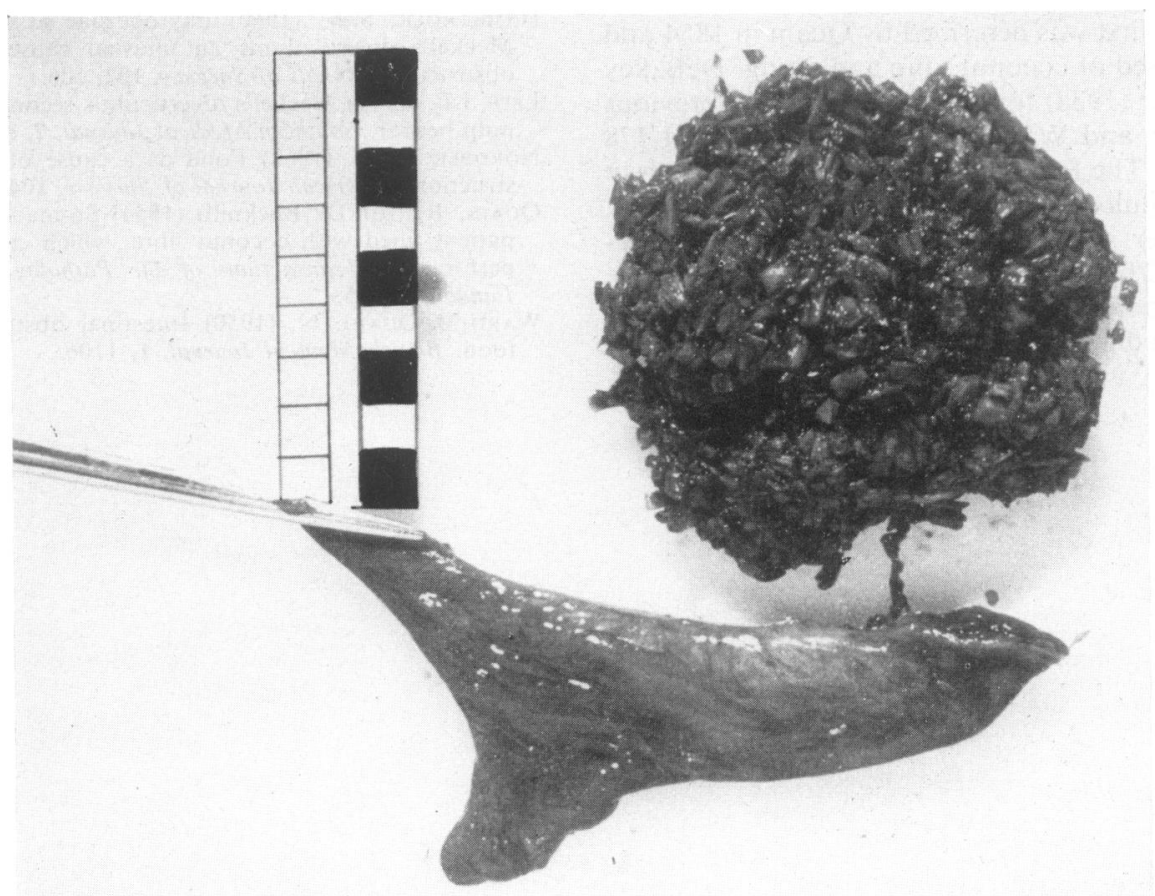

FIG. 1. Resected bowel with diverticulum and removed mass of coconut. 0032-5473/82/0200-0119 $\$ 02.00$ (C) 1982 The Fellowship of Postgraduate Medicine 
tenderness. His bowel sounds were normal. His rectum was empty and his right pouch of Douglas was tender, but no definite mass could be felt.

With the impression that this was a case of pelvic appendicitis, and that the history of coconut ingestion was incidental, he was taken to theatre.

\section{Operative findings}

Through a right gridiron incision clear peritoneal fluid was seen and a normal appendix was removed. The terminal ileum was oedematous, congested and contained large amounts of inspissated vegetable fibre (coconut). This was in 3 large boluses all of which were proximal to a large, wide mouthed Meckel's diverticulum found about $60 \mathrm{~cm}$ from the ileocaecal valve.

The bezoar would not easily pass into the caecum so most was removed with $20 \mathrm{~cm}$ of resected small bowel, including the diverticulum (Fig. 1).

\section{Comment}

There have been 2 previous reports of Meckel's diverticulum presenting with intestinal obstruction due to phyto-bezoar. In the first, the bezoar was sauerkraut (Hamburger, 1960), in the second, it was formed of orange pulp (Leff, 1979).

Bezoars of the intestinal tract are unusual occurrences. The first was described by Quain in 1854 and was composed of coconut fibre and string. DeBakey and Ochsner (1938) found 311 examples in previous publications and Ward-McQuaid (1950) found 178 more cases. The foods implicated are always rich in fibre and cellulose, and meat has never been reported. Of the latter study, 30 cases were caused by persimmons, 22 by citrus fruits, 18 by peaches $(10$ dried), 9 by mushrooms, 8 by bran and 7 by apples ( 3 dried). Obstruction due to bezoar is very rare in the anatom- ically normal gut; congenital abnormalities and any 3 abdominal surgery, but particularly gastric resection, $\stackrel{\triangleright}{\unrhd}$ are the common predisposing factors (Nordberg, $C$. 1962), particularly in the edentulous patient, $\vec{F}$ because of difficulty in chewing and loss of buccal $\stackrel{5}{+}$ sensation.

Of interest in this patient is the fact that the $\frac{\overline{\bar{O}}}{\overline{6}}$ bezoar was apparently arrested before it had $\frac{\mathcal{N}}{\sigma}$ reached the Meckel's diverticulum (which was not $\cong$ inflamed, no coconut having entered or passed it). ڤ Whilst the patient had none of the signs, and only $\vec{A}$ vomiting as a possible symptom of obstruction, the coconut's progress was apparently stopped by the $\vec{\omega}$ Meckel's diverticulum and it was thought that the diverticulum had caused inco-ordination of theo peristaltic wave preventing passage of the mass of 3 . coconut.

\section{Acknowledgments}

I thank Professor F. Ashton for his help in the preparation $\overrightarrow{\vec{\theta}}$ of this case.

\section{References}

DeBAKey, M. \& OChSNer, A. (1938) Bezoars and concretions: comprehensive review of literature with analysis of $303 \frac{\mathrm{C}}{\mathrm{C}}$ cases and presentation of 8 additional cases. Surgery, 4 , 934.

HAMBurger, S.W. (1960) Phytobezoar associated with $\stackrel{\partial}{\vec{a}}$ Meckel's diverticulum: an unusual cause for intesting $\infty$ obstruction. Annals of Surgery, 152, 106.

LEFF, I.E. (1979) Meckel's diverticulitis secondary to orange pulp bezoar. Southern Medical Journal, 7, 888.

NordBerg, P.B. (1962) Food as a cause of intestinal obstruction. American Journal of Surgery, 104, 404.

QuAIN, R. (for Dr Bucknill) (1854) Stomach of an insane patient filled with coconut fibre, which caused death by $\frac{O}{\mathbb{D}}$ perforation. Transactions of the Pathological Society of 2 London, 5, 145.

WARD-MCQUAID, N. (1950) Intestinal obstruction due to $\frac{\mathrm{O}}{3}$ food. British Medical Journal, 1, 1106. 